\title{
Critical Factors Affecting Bank Management Policies
}

\author{
FRANCESCA PAMPURINI \\ Department of Economic and Social Sciences \\ Catholic University of the Sacred Heart of Milan \\ Via Emilia Parmense 84, 29122 Piacenza \\ ITALY
}

\author{
ANNA GRAZIA QUARANTA \\ Department of Economic and Law \\ University of Macerata \\ Via Armaroli 43, 62100 Macerata \\ ITALY
}

\begin{abstract}
We suggest some managerial implications following the identification of the determinants of the best efficiency levels achieved by banking groups in the main Euro Area countries in the period 2009-2018, using a cluster analysis. Differently from previous works, this study analyzes the banking groups' behavior in a particularly interesting period characterized by the sequence of three very different crises: the sub-prime, the sovereign debt and the NPLs crises. The results show that the best performances are linked to a particular business model, to specific managerial decisions, such as the achievement of a medium size along with a rational valuation of the number of firms in the same banking group and to suitable cost rationalization strategies and liquidity reserve optimization policies. All the results obtained support empirical evidences already highlighted in the existing literature.
\end{abstract}

Key-Words: - Banking; Efficiency; Parametric Approach; Cluster Analysis; Business Models; Management Implications.

Received: March 1, 2020, Revised: July 31, 2020. Accepted: August 9, 2020. Published: August 13, 2020.

\section{Introduction}

The issue of bank efficiency and, more generally, of the efficiency of the whole banking system is a topic that has deep origins in scientific literature. In recent decades, a great number of studies suggested an analysis of the level of efficiency of banks and financial intermediaries in order to highlight the impact of various phenomena through an intertemporal comparison ([1], [2], [3], [4], [5]) and in order to identify the causes of the changes, ([6], [7], [8], [9], [10], [11]).

The 2008 Global Financial Crisis was probably the most tragic event of the last decade which deeply changed the strategic behavior of the banks operating in the countries affected by the crisis and which revealed the aptitude of the banking industry to take on excessive risks with respect to poor liquidity and capital reserves. In addition, it is also important to note that the level of prudence was completely inadequate ([12]; [13]).

The Regulatory Authorities reacted and introduced stronger requirements for capital and liquidity and completely redrafted the resolution schemes for problematic cases. To respond to the new prudential rules and to the changes of the banking environment, the banks had to vigorously redefine their strategies and their business models to face a new system characterized by unusually low profitability levels. As is well known, the restructuring process of the banking system is still underway. Among the main results of a recent study of the Bank of International Settlements [12] we notice a propensity to rethink the business model, moving from a high level of trading activity and, more generally, from a business based mainly on financial services, to a structure that is more oriented towards traditional lending. Again, 
from a funding point of view, we note the tendency to decrease recourse to wholesale funding in favor of more traditional retail deposit funding. At the same time, the issue of dramatically low levels of profitability is set to remain as a structural dilemma for the whole system and a topic that the banks will be called upon to deal with, even in the near future. Low levels of profitability are not necessarily considered pathological since they arise from different strategic factors: idiosyncratic factors, such as the choice of a particular business model, and economic factors, such as the level of interest rates and the dynamic of structural economic growth.

We have to remember that the recent innovations regarding prudential regulation reduced the discretion with which banks could take on risk, so, as a consequence, a riskless business generates lower returns, especially when compared to pre-crisis levels.

In light of the structural changes that are transforming the face of the banking system after the global financial crisis, it is essential to observe the dynamics of banks' efficiency indicators for at least two reasons: to extract useful information about the health of the whole system and to identify the critical factors that could generate an increase (or a decrease) in efficiency levels.

As already outlined by previous literature [14], as yet, few studies have focused on the dynamic of profitability and efficiency and on their interaction ([15], [16]), of the European banking system after the global crisis ([17]). An analysis of the banks' response to the incentives from the external environment and an evaluation of the effectiveness of their choices in terms of efficiency enables us to deduce important information that is useful both for managers, who are looking to implement new strategies for growth and development, and for policymakers, who are trying to define a regulatory scheme based on different instruments which can take into account the purpose of the regulation and of the environment that characterizes the system.

Differently from previous works, this study analyzes the banking groups' behavior in a particularly interesting period characterized by the sequence of three very different crises: the sub-prime, the sovereign debt and the NPLs crises. In particular, we look at banking groups operating in the main countries of the Euro Area in the period 2009-2018. The aim is to offer some useful managerial and policy recommendations after identifying the possible determinants of the highest efficiency values obtained by banking groups.

Using this timeframe allows us to capture the impact of the variables that we analyze as possible determinants of the degree of efficiency of the banking groups during the crisis period and over the following years.

The study is organized as follows: Section 2 outlines the results while Section 3 offers a discussion of the results providing some managerial implications. Section 4 presents our conclusions.

\section{Results}

The pool of banking groups considered for the analysis consists of 73 units operating in the main Euro Area countries characterized by a nondissimilar socio-economic profile. For reasons of comparability of results, we used a balanced data set including 9 Austrian banking groups, 3 Belgian, 16 German, 11 Spanish, 8 French, 14 Italian, 10 Dutch and 3 Portuguese.

The values of the efficiency indices of the groups were obtained via a methodology widely used in literature ([18], [19]) and already implemented, although with different purposes, in our previous studies. Briefly, for each year under review, we used a stochastic cost frontier in a translog, and therefore a parametric procedure within which the total production costs were regressed on three outputs and four inputs defined coherently with the intermediation approach [18].

Given this premise, we obtained banking groups' inefficiency values for each year as regression residuals. The obtained values show clearly that, each year, the variability between the average values of the efficiency indices related to each country is very low. From the analysis of these values, the level of the banking groups' efficiency in the period of analysis clearly tends to decrease and therefore to reflect the effect on efficiency by low profitability and by the high incidence of costs.

Analyzing the trend of the aforementioned efficiency values, the impacts of the events that have marked the last decade are particularly evident. After the first slight recovery that characterized the period immediately following the outbreak of the global crisis, we observe a first significant decrease between 2011 and 2012 due to the problems linked to the sovereign debt crisis that hit several continental European countries causing significant widening of spread.

A second important decrease in the level of efficiency characterized the period 2013-2014. This trend reflected the impact of problems deriving both from the persistence of the residual negative effects of the sovereign debt crisis and from the emergence of nonperforming loans in the balance sheets of many intermediaries. 
In 2015 and 2016, there were no significant changes in average efficiency levels which, on the other hand, underwent a moderate decline in 2017 , probably due to the effects of the bail-in rules. In 2018, there was a slight recovery in average values.

An interesting result can also be observed by analyzing the efficiency indices related to groups of different size. Throughout the period analyzed, the efficiency level of the large groups is systematically lower than that of the other two size categories. The medium-sized groups in any case performed the best in terms of efficiency. This result is not surprising since many studies observed the same evidence ([1], [20], [21], [22], [23], [24], [25], [26]).

Using the efficiency values of each banking group in each year, we ran a non-hierarchical (k-means) cluster analysis to divide the units into three homogeneous groups, that is, by distinguishing the banking groups that showed lower, medium and higher overall efficiency values throughout the period of the study.

Table 1. Determinants of efficiency and their related analysis profiles.

\begin{tabular}{|l|l|c|}
\hline \multicolumn{1}{|c|}{ Analysis Profiles } & \multicolumn{1}{c|}{ Variables used } & Significant \\
\hline Size & Total Assets & yes \\
\hline Liquidity & Liquid Assets / Total Assets & yes \\
& Liquid Assets / Deposits and short-term Funding & no \\
\hline Intangible Assets & Intangibles / Total Assets & yes \\
\hline Profitability & Profit before Tax / Total Assets & yes \\
& Operating Profit / Average Total Equity & yes \\
& ROAA & yes \\
& Net Interest Income / Earning Assets & yes \\
\hline Efficiency & Cost to income ratio & yes \\
\hline Funding Composition & Deposits and short-term funding / Total Funding & no \\
\hline Business Model & Loans / Total Assets & yes \\
& Total Financial Assets / Total Assets & yes \\
\hline Complexity of the Group & Number of companies in the Group & yes \\
\hline Listed/Unlisted & Dummy Variable & yes \\
\hline Risk/Capitalization & Total Capital Ratio & yes \\
\hline
\end{tabular}

Table 2. Average values (in percentage) of the considered variables in each cluster.

\begin{tabular}{|l|l|r|r|r|}
\hline & & CLUSTER & \multicolumn{1}{|c|}{$\begin{array}{c}\text { CLUSER } \\
\mathbf{2}\end{array}$} & $\begin{array}{r}\text { CLUSTER } \\
\mathbf{1}\end{array}$ \\
\hline \multirow{3}{*}{ Size } & Small & 17 & 45 & 17 \\
& Medium & 61 & 35 & 33 \\
& Large & 22 & 20 & 50 \\
\hline Liquidity & Liquid Assets / Total Assets & 21.24 & 27.58 & 30.20 \\
\hline Intangible Assets & Intangibles / Total Assets & 0.33 & 0.39 & 0.35 \\
\hline \multirow{2}{*}{ Profitability } & Profit before Tax / Total Assets & 0.57 & 0.56 & 0.54 \\
\cline { 2 - 5 } & Operating Profit / Average Total Equity & 6.67 & 6.44 & 6.84 \\
\cline { 2 - 5 } & ROAA & 0.43 & 0.25 & 0.48 \\
\cline { 2 - 5 } & Net Interest Income / Earning Assets & 1.60 & 1.77 & 1.98 \\
\hline Efficiency & Cost to Income Ratio & 67.03 & 69.22 & 71.01 \\
\hline \multirow{2}{*}{ Business Model } & Loans / Total Assets & 67.53 & 56.40 & 52.40 \\
\cline { 2 - 5 } & Total Financial Assets / Total Assets & 15.90 & 17.86 & 18.71 \\
\hline \multirow{2}{*}{$\begin{array}{l}\text { Complexity of } \\
\text { Group }\end{array}$} & Number of companies in the Group & 166 & 334 & 1302 \\
\hline Listed/Unlisted & Listed Groups & & & \\
\hline Risk/Capitalization & Total Capital Ratio & 0.46 & 0.42 & 0.46 \\
\hline
\end{tabular}

As is already known, cluster analysis, unlike other multivariate statistical techniques, does not make any a priori assumption on the existing fundamental typologies that can characterize the statistical units studied. The technique is, in fact, a purely empirical classification method and, as such, it is an inductive procedure, which plays an exploratory role in the search for latent structures in order to infer the most 
probable partition of the units. In addition, hierarchical approaches based on different grouping algorithms and different distance measures were also tested. Among these, we also employed the wellknown Ward method, but the results obtained were completely consistent.

As for the determinants of the efficiency levels reached by the groups, we considered the values of the main variables suggested by other studies (see Table 1) as possible determinants of groups' efficiency. The last column of Table 1 shows the variables that provided significant information.

Table 2 shows the average values reached by the mentioned variables in each cluster giving, at the same time, a profile for each of them.

\section{Discussion}

Some important reflections emerge regarding managerial and strategic decisions and their impact on the results in terms of efficiency.

Regarding the issue of size, it can be seen that the best results in terms of overall efficiency gained over time are attributable to medium-sized banking groups, while half of large groups are in the third cluster that displays the worst overall efficiency levels.

Previous studies ([22], [23], [24], [27]) had already highlighted that the increase in size also increased the organizational and management complexity of banking and financial groups, thus generating a negative impact on the overall efficiency level of the whole poly-functional group. In our case, this result is also confirmed by the fact that the groups that showed the worst overall results in terms of efficiency are also those for which the complexity level has the highest value, even almost ten and four times higher than those, respectively, of the banking groups in the first and second clusters.

A further confirmation of this link between the level of efficiency and the size and complexity of banking groups derives from the cost-to-income ratio analysis. The most efficient groups are those for which this indicator registers the lowest levels, emphasizing once again the importance of containing costs at a strategic level. This indicator increases progressively, moving from the first to the third cluster, supporting the hypothesis that the dimensional increase and the resulting management complexity lead to scale diseconomies ([16], [23]).

Another feature that seems to positively influence the overall level of efficiency concerns the choice of business model; a positive link emerges between the effect of traditional lending business on the overall business and the level of efficiency achieved. The groups that have chosen to adopt (or maintain) a traditional business model based on the centrality of lending activities are those that have the best overall efficiency levels. On the contrary, the overall less efficient banking groups are characterized by a higher recourse to investment banking and trading. This result is also in line with the main findings of other studies ([12], [23], [24], [28]).

Another strategic choice that seems to have an impact on efficiency is in the field of liquidity policy. In the analysis conducted, the groups showing the highest levels of overall efficiency show lower liquidity levels than all the others. This naturally leads us to reflect on liquidity costs and therefore, once the minimum coefficients imposed by the rules recently introduced by the Basel legislator are met, managers should be stimulated to use any liquidity excess on more profitable assets.

As regards the intermediate values of the two variables operating profit to total equity and ROAA, they must be interpreted as a direct consequence of what we previously discussed. The same reasoning applies to the particularly low values of group complexity reached by the most efficient banking groups. This could be because these are variables that cannot be controlled directly by managers since they derive from the strategic choices discussed above and from the business model adopted.

The absence of a well-defined link between cost efficiency and some of these aspects such as, for example, the effect of net interest income on earning assets and level of risk, is not surprising. In fact, these indices largely depend on the conditions of the external environment which all banking groups must deal with. In fact, the effect of net interest income on earning assets was certainly influenced by the exceptionally low level of market interest rates (in some periods even negative) which drastically eroded interest rate spread. Total capital ratio, on the other hand, is an index with a minimum threshold defined by the Supervisory Authorities starting from which each management identifies its own level of compliance trying not to deviate too far from the average of the index levels fixed by competitors.

\section{Conclusions}

In this final section we try to summarize the most evident managerial and policy indications deriving from the results of the analysis.

The results clearly show that the banking groups that reached the highest overall efficiency values over time are those of medium size, consisting of a not particularly high number of companies and characterized by a business model that is more 
oriented than the others to traditional credit activity. These groups are also distinguished by a greater ability to reduce costs and by a limited weight of both liquidity and financial assets on total assets.

Regarding liquidity, this is perfectly in line with the opportunity to maintain non-excessive amounts in the portfolio, thus avoiding rather high opportunity costs but, at the same time, guaranteeing sufficient stock to adequately manage the problems that would be generated in case of a crisis in the markets.

The choice to move towards a more traditional business model is also crucial. Following the outbreak of the crisis and the contagion phenomena between different countries and different industrial sectors, many banking groups changed their activity by reducing the size of loans - to the detriment of the credit flow in support of the real economy - and thus moving towards the investment bank model, with the aim of countering the reduction in interest margin by increasing revenues from commissions and services. This choice, indeed, only produced an increase in profitability in the first few years and, conversely, simultaneously increased the volatility of the sources of revenue. In the medium-long term, this strategy therefore proved to be relatively unwise, so many banking groups have gradually returned to a traditional business based on lending to retail customers.

The modulation of the size of financial assets also appears to pose problems. If, on the one hand, lending activity below a certain threshold would inevitably generate problems of low profitability, on the other, its disproportionate increase would lead to adverse selection phenomena with negative impacts, once again, on profitability. Maintaining this delicate balance is probably the reason why the profitability

\section{References:}

[1] Allen, L., \& Rai, A. (1996). Operational efficiency in banking: An international comparison, Journal of Banking and Finance 20 (4), 655-672.

[2] Berger, A. N., \& Mester, L. J. (1997). Inside the black box: What explains differences in the efficiencies of financial institutions, Journal of Banking and Finance 21 (7), 895-974.

[3] Bauer, P. W., Berger, A. N, Ferrier, G. D., \& Humphrey, D. B. (1998). Consistency Conditions for Regulatory Analysis of Financial Institutions: A Comparison of Frontier Efficiency Methods, Journal of Economics and Business 50 (2), 85-114.

[4] Coelli, T. J., Rao, D.S.P., O'Donnell, C.J., \& Battese, G.E. (2005). An Introduction to Efficiency and Productivity Analysis, Springer, Berlin.

[5] Beccalli, E., Casu, B., \& Girardone, C. (2006). Efficiency and Stock Performance in European indicators of the most efficient groups are at intermediate levels compared to those of the groups belonging to the other two clusters.

In addition, from the point of view of cost containment, the most efficient groups overall over time are those for which the cost-to-income ratio is lower, although the difference from the average value reached in the same index by the medium-efficiency banking groups does not appear particularly marked. The most efficient banking groups also show intermediate values for the ratio between operating profit and average total equity and of ROAA. Moreover, they have the highest profit before tax values and, at the same time, show the lowest level of complexity of the group.

All the strategic choices in some way linked to the search for an adequate dimension are therefore of primary importance; in any case, this must be achieved by remodeling the complexity of the group towards a more streamlined and thus a more effective and efficient structure. To this must be added adequate cost rationalization policies, the optimization of asset liquidity levels as well as the search for a business model that is able to provide the most appropriate balance of credit and financial activities.

The importance of this last point shows the need for greater attention to the identification of indices different from those now generally used - which are able to efficiently represent the business model. This is because the consolidated data is not always automatically explanatory of the choice of the model adopted within a banking group.

Banking, Journal of Business, Finance and Accounting 33 (1-2), 245-262.

[6] Halkos, G. E., \& Tzeremes, N. G. (2013). Estimating the degree of operating efficiency gains from a potential bank merger and acquisition: a DEA bootstrapped approach, Journal of Banking and Finance 37 (5), 1658-1668.

[7] Barra, C., Destefanis, S., \& Lubrano Lavadera, G. (2016). Risk and regulation: A difference-indifferences analysis for Italian local banks. Finance Research Letters, 17, 25-32.

[8] Quaranta, A.G., Raffoni, A., \& Visani, F. (2018). A multidimensional approach to measuring bank branch efficiency, European Journal of Operational Research 266, 746-760.

[9] Pampurini, F., \& Quaranta, A.G. (2018). Sustainability and Efficiency of the European Banking Market after the Global Crisis: The Impact 
of Some Strategic Choices, Sustainability 10, 2237 (1-16).

[10] Nagaraju, T., \& Subrahmanyam, A. C. V. (2019). Bank total factor productivity convergence: Evidence from India. Finance Research Letters In press, corrected proof Available online 12 November 2019, Article 101357.

[11] Pagano, M.S. (2020). The shrinking role of foreign operations at global financial institutions and its impact on efficiency. Finance Research Letters, In press, corrected proof Available online 11 January 2020, Article 101419.

[12] Bank for International Settlements (2018). Structural changes in banking after the crisis, CGFS Papers 60.

[13] Rossignolo, A.F., Fethi, D.M., and Shaban, M. (2014): Merket crisis and Basel capital requirements: could Basel III have been different? Evidence from Portugal, Ireland, Greece and Spain (PIGS), Journal of Banking and Finance 37, 1323-1339.

[14] Tsionas, E.M., Assaf, A.G. \& Matousek R. (2015). Dynamic technical and allocative efficiencies in European banking, Journal of Banking \& Finance 52, 130-139.

[15] Phan, H. T., Anwar, S., \& Alexander, W. R. J. (2018). The determinants of banking efficiency in Hong Kong 2004-2014, Applied Economics Letters 25 (18), 1323-1326.

[16] Lu, Y. F., Gan, C., Hu, B., Toh, M. Y., \& Cohen, D. A. (2018). Bank efficiency in New Zealand: a stochastic frontier approach, New Zealand Economic Papers.

[17] Martins, A.I. (2018). Efficiency determinants in Portuguese banking industry: an application through fractional regression models, Tourism and Management Studies 14 (2), 63-71.

[18] Berger, A. N., \& Humphrey, D. B. (1997). Efficiency of financial institutions: International survey and directions for future research, European Journal of Operational Research 98 (2), 175-212.

[19] Beccalli, E. (2004). Cross-country comparisons of efficiency: Evidence from the UK and Italian investment firms, Journal of Banking and Finance 28 (6), 1363-1383.

\section{Contribution of individual authors to the creation of a scientific article (ghostwriting policy)}

Francesca Pampurini and Anna Grazia Quaranta built up the data-set together, they implemented the models together and wrote the whole paper together.
[20] Avramidis, P., Cabolis, C., \& Serfes, K. (2016). Does one bank size fit all? The role of diversification and monitoring, LeBow College of Business, Drexel University School of Economics Working Paper Series 7.

[21] Delis, M.D., Iosifidi, M., \& Tsionas, M.G. (2017). Endogenous bank risk and efficiency,

European Journal of Operational Research 260, 376-387.

[22] Isik, I., \& Hassan, M. K. (2002). Technical, scale and allocative efficiencies of Turkish banking industry. Journal of Banking and Finance 26 (4), 719-766.

[23] Batir, T. E., Volkman, D. A., \& Gungor, B (2017). Determinants of bank efficiency in Turkey: Participation banks versus conventional banks, Borsa Istanbul Review 17-2, 86-96.

[24] Mesa, R. B., Sánchez, H. M., \& Sobrino, J. N. R. (2014). Main determinants of efficiency and implications on banking concentration in the European Union, Spanish Accounting Review 17 (1), 78-87.

[25] Andries, A. M. (2011). The determinants of bank efficiency and productivity growth in the central and eastern European banking systems, Eastern European Economics 49 (6), 38-59.

[26] Goddard, J., Molyneux, P., Wilson, J.O., \& Tavakoli, M. (2007). European banking: an overview. Journal of Banking and Finance 31, 19111935.

[27] Catalbas, G. K., \& Atan, M. (2005). Efficiency in banking and the effect of capital structure efficiency in banks, Journal of Economics Business and Finance 20 (237), 49-62.

[28] Doan, A.T., Lin, K.L., \& Doong, S.C. (2018). What drives bank efficiency? The interaction of bank income diversification and ownership, International Review of Economics and Finance 55 203-219.

\section{Creative Commons Attribution License $\quad 4.0 \quad$ (Attribution $\quad \mathbf{4 . 0}$ International, CC BY 4.0)}

This article is published under the terms of the Creative Commons Attribution License 4.0 https://creativecommons.org/licenses/by/4.0/deed.en _US 